\title{
ADOLESCENCE AND LATER LIFE DISEASE BURDEN: QUANTIFYING THE CONTRIBUTION OF ADOLESCENT TOBACCO INITIATION FROM LONGITUDINAL COHORTS
}

Authors:

Russell M. Viner PhD

Population, Policy \& Practice Research Programme, UCL Institute of Child Health, 30 Guilford St. London, WC1N 1EH, UK. r.viner@ucl.ac.uk

Dougal S. Hargreaves MD(Res)

Population, Policy \& Practice Research Programme, UCL Institute of Child Health, 30 Guilford St. London, WC1N 1EH, UK. d.hargreaves@ucl.ac.uk

Janaina Vieira dos Santos Motta PhD

Postgraduate Program in Health and Behavior, Universidade Católica de Pelotas, R. Gonçalves Chaves 373/411, Centro, Pelotas, Brazil. jsantos.epi@gmail.com

Bernardo Horta PhD

Postgraduate Program in Epidemiology, Universidade Federal de Pelotas, Rua Marechal Deodoro 1160 - 3 andar, 96020-220, Pelotas, Brazil. blhorta@gmail.com

Ali H. Mokdad PhD

Institute for Health Metrics and Evaluation, University of Washington, 2301 5th Avenue, Suite 600 Seattle, WA 98121 USA. mokdaa@uw.edu

George Patton MD

Centre for Adolescent Health, Murdoch Children's Research Institute, Royal Children's Hospital, University of Melbourne, Melbourne, Australia. george.patton@rch.org.au

\section{Correspondence}

Prof. Russell Viner

UCL Institute of Child Health

30 Guilford St.

London WC1N 1EH

Tel: 02079052362

R.Viner@ucl.ac.uk

All authors declare no conflicts of interest.

No funding was obtained for these analyses.

The first draft of this paper was written by RV. 


\section{Abstract}

\section{Purpose}

Adolescence is a time of initiation of behaviours leading to non-communicable diseases (NCDs). We use tobacco to illustrate a novel method for assessing the contribution of adolescence to later burden.

Methods

Data on initiation of regular smoking during adolescence (10-19 years) and current adult smoking were obtained from the 1958 British Birth Cohort, the US National Longitudinal Study of Adolescent Health (Add Health), the Pelotas 1982 Birth Cohort and the Victorian Adolescent Health Cohort Study (VAHCS). We estimated an 'Adolescent Attributable Fraction' (AAF) by calculating the proportion of persisting adult daily smoking initiated < age 20. We used findings to estimate AAFs for $>155$ countries using contemporary surveillance data.

\section{Results}

In the 1958 British Birth Cohort, 81.6\% of daily smokers at age 50 years initiated <age 20, with a risk ratio (RR) of 6.1 for adult smoking related to adolescent initiation. The adjusted AAF was 69.1. Proportions of smokers initiating $<20$ years, RR and AAFs were $83.3 \%, 7.0$ and 70.4\% for Add Health; 75.5\%, 3.7 and 50.2\% in VAHCS; and 70.9\%, 5.8 and 56.9\% in Pelotas males and $89.9 \% ; 6.4$ and $75.9 \%$ in females. Initiation $<16$ years resulted in the highest AAFs. Estimated AAFs globally ranged from $35 \%$ in China to $76 \%$ in Argentina.

\section{Conclusions}

The contribution of adolescent smoking initiation to adult smoking burden is high, suggesting a need to formulate and implement effective actions to reduce smoking initiation in adolescents. Similar trends in other NCD risks suggest that adolescents will be central to future efforts to control NCD's.

\section{Keywords}

\section{Adolescent}

Attributable fraction

Etiologic fraction

Tobacco

Non-communicable disease 


\section{Implications and Contribution summary}

Risks for many NCDs arise in adolescence yet these have not been quantified.

We show that the proportion of adult smoking that would be prevented if initiation was prevented during adolescence ranges from $50-72 \%$ across countries.

Tobacco control initiatives should be rebalanced to include a greater focus on adolescent initiation and early smoking cessation. 


\section{Background}

Many risk factors for non-communicable disease (NCD) burden are initiated in adolescence, with 2 of the 5 leading risk factors (tobacco and alcohol) for global disability adjusted life years (DALYS) loss predominantly initiated in adolescence.(1) Approximately $80 \%$ of life-time smoking initiation occurs before age 20 years in high income countries, with younger cohorts beginning even earlier(2) and similar patterns now emerging in many low and middle income countries (LMIC).(2, 3) However actions to prevent NCD risk factors in adolescence have been limited. Current global activities on NCD prevention and the emerging United Nations Sustainable Development Goals (SDGs) focus on prevention of premature mortality in adults with established risk factors. $(4,5)$

One reason for this limited focus on adolescence is a lack of clarity over the preventive potential of adolescent interventions. While most smokers begin in adolescence, some are only transient smokers, many quit across early adulthood and there are temporal trends in adolescent and adult smoking rates and in adult quitting. While there is a large literature supporting the importance of prevention in adolescence,(6) it has been difficult to quantitate the preventive potential of intervention in adolescence.

We propose a method of estimating the adolescent contribution to adult burden through calculation of the population attributable fraction (PAF) of adolescent exposures for later burden. The PAF is the proportional reduction in population levels of a disease or mortality that would occur if exposure to the risk factor in question were reduced to an ideal alternative, usually nil.(1, 7) PAFs may be calculated for a behavioral exposure and a second behavioral outcome. $(8,9)$ Here we define a behaviour initiated in adolescence as the 'exposure' and calculate the PAF of the adult disorder/behaviour related to adolescent initiation of the behaviour, which can be conceptualized as an Adolescent Attributable Fraction (AAF). 
Here we use tobacco, the key priority for global action on NCDs,(4) to illustrate estimation and use of AAFs. We use adult smoking prevalence as a proxy for smoking related burden, given its identification as the most important global target for tobacco control.(10) Our aim was to identify the proportion of global tobacco burden that might be prevented through intervention in adolescence. We used data from longitudinal cohorts from high and middle income countries to estimate AAFs for adult smoking with varying ages of initiation and heavy as well as regular smokers. We then used these data to estimate contemporary AAFs for adult smoking for 19 LMIC using data from the Global Adult Tobacco Survey (GATS) from 2008-2012 and for 155 LMIC using recent data from the Global Youth Tobacco Survey (GYTS), and to model the impact on AAFs of temporal trends in adolescent and adult smoking rates and of reducing adult smoking to more pragmatic scenarios such as the $5 \%$ target identified by the Lancet NCD Group(5).

\section{METHODS}

Three sets of analysis were undertaken. We first used data from four national or regional longitudinal cohorts which provided data on age of initiation of smoking from adolescent waves and data on adult smoking beyond age 25 years.

The British National Childhood Development Study (NCDS)(11) is a nationally representative birth cohort which followed all UK children born in 1 week in $1958(n=17,638)$ and followed them up frequently till age 50 years (2008).

The U.S. National Longitudinal Study of Adolescent to Adult Health (Add Health)(12) is a nationally representative longitudinal cohort which recruited young people in grades 7-12 (secondary school) during 1994-95 (wave 1) and followed them up most recently in 2007-08 (age 24-34 years, wave 4). 
The 1982 Pelotas birth cohort study enrolled all children born in a medium-size city in southern Brazil in 1982 ( $n=5914)$ and followed them to age 30 years (2012-13), with selfreport data on smoking habits provided at ages $18,22-23$ and 30 years. The Pelotas cohort is unique amongst LMIC in its breadth, low attrition rate and length of follow-up into adult life.(13)

The Victorian Adolescent Health Cohort Study (VAHCS)(14) is a cohort study that recruited nearly 2000 adolescents aged 14-16 years in Victoria, Australia, in 1992. Participants were followed up in 6 waves during adolescence (14-20 years) and 4 waves in young adulthood, with wave 10 in 2013 at a mean age of 35 years ( 33 to 40 years). For further details on cohorts see Appendix.

In each cohort, we used data on smoking from adolescent waves together with retrospective reporting of age of initiation from adult waves to assign individuals to an age of initiation of regular smoking. "Data on smoking in adolescence were taken from the most contemporary adolescent waves for each survey. NCDS: age 16 and 23 year cohorts; Add Health: Wave 1 (mean age 16yr, range 11 to 23 years) and completed from Waves 2- 4 data as the cohort aged; Pelotas: data surveys at 18,19 and $22-23$ years; VACHS: data at each wave from 1 (1316 years) through 6 (age $16-19$ years)."

Smoking in adolescence was defined as any regular smoking approximately weekly or more often in the NCDS, Pelotas and VAHCS and daily smoking in Add Health (smoking > 20 days a month). Adult daily smoking was defined as regular smoking $\geq 1$ cigarette per day in the NCDS, Pelotas and VAHCS cohorts and $>25$ days per month in Add Health. Heavy smoking was defined as regular consumption of $\geq 20$ cigarettes per day in all cohorts. Persistent smokers in the NCDS were those who were regular smokers in 2 out of 3 waves from age 33 to 50 years. 
Socioeconomic status variables used included: NCDS: father's social class in adolescence and own social class in adulthood ii) Add Health: household income in wave 4; iii) Pelotas: socioeconomic level categorized into five groups; iv) VAHCS: highest educational level achieved by wave 10 .

We first calculated unadjusted AAFs according to the standard Levin's formula for PAF:

$P A F=P e(R R-1) /(1+P e(R R-1))$

where $\mathrm{Pe}$ is the proportion of the population exposed to the risk factor and RR is the relative risk,(15) using the cs (provides cohort study tables) command in Stata 13. We then calculated AAFs adjusted for socioeconomic status and sex(15) using the punaf command (calculates PAFs),(16) after running a logistic regression model with adult smoking as the dependent variable and adolescent smoking, sex and socioeconomic status as predictor variables. Analyses were reported separately by sex where significant differences in AAFs were found between males and females.

The cohorts provide the necessary longitudinal data to calculate the strength of association between adolescent smoking initiation and current adult smoking, allowing for quitting and relapse. We therefore used findings from the cohorts to estimate AAFs for subsequent analyses including a much wider range of countries for which there are cross-sectional data on either the current prevalence of smoking in adolescence $(P e)$ or the proportion of current smokers who initiated in adolescence $(P d)$.

The second analyses estimated AAFs for adult smoking using GATS data collected from 2008 - 2012 across 19 LMIC: Bangladesh, India, Indonesia, Thailand, China, Malaysia, Philippines, Viet Nam, Nigeria, Egypt, Poland, Romania, Russian Federation, Turkey, Ukraine, Argentina, Brazil , Mexico and Uruguay. GATS is a cross-sectional household-based survey designed to obtain nationally representative data in low-income and middle-income countries for the 
tobacco use behaviours of individuals aged 15 years and older (see Appendix). GATS

included questions on age smokers began smoking daily and allowed us to calculate a PAF as a function of exposed cases (Pd), here the proportion of adult smokers who initiated in adolescence:(17)

$P A F=P d((R R-1) / R R)$

To estimate AAFs for each GATS country, we first calculated the proportion of smokers who initiated regular daily smoking < age 20 years. We used the most contemporary cohort in whom adult smoking had stabilized(2) i.e. 25-34 years. As the cross-sectional GATS data did not allow calculation of RR, we used the range of RR identified from our longitudinal analyses to estimate AAFs. Use of alternative RR from source cohorts is common where exposure prevalence but not RR are known in target populations.(18)

Thirdly we obtained data on current adolescent smoking prevalence from the Global Health Observatory of the World Health Organization. Available data were current smoking (any tobacco use in last 30 days) in 13-15 year olds in 155 countries, predominantly data from the GYTS undertaken in $151 \mathrm{LMIC}(19)$ (see Appendix). GYTS therefore provide an estimate of current adolescent smoking $<16$ years as the exposure $(P e)$ allowing us to use Levin's formula to estimate AAFs for the range of realistic RR.

Finally, we repeated examined the effect on the calculated AAFs of choosing counter-factual scenarios of reducing adult smoking prevalence to $5 \%$ through to $15 \%$. 


\section{RESULTS}

Data on smoking adulthood by smoking status in adolescence (10-19 years) are shown for each cohort (the NCDS at 50 years and persistent adult smoking, Add Health, VACHS and Pelotas cohorts) in Table 1. For each cohort, the Table shows the proportion of adult smokers who initiated regular smoking in adolescence $<20$ years together with the associated risk ratio (RR) for being an adult smoker related to adolescent smoking, the adolescent attributable fraction (AAF) for adult smoking, and the adjusted AAF (adjusted for socioeconomic status and sex). Data for the Pelotas cohort differed notably by sex and are reported for males and females separately. Data relating to adult smoking and adolescent initiation at either $\leq 16$ years or 17-19 years are shown in Table 2 and data for the NCDS at ages 33 and 42 years are shown in Appendix Table A1.

In the NCDS, the proportion of adult smokers who initiated in adolescence rose from $75 \%$ at age 33 to $82 \%$ at 50 years, with consequent rises in the RR and therefore the AAFs, which peaked at $69 \%$ at age 50 years. The AAF for persistent smoking was highly similar to those for 42 and 50 years. AAFs were uniformly higher for initiation of smoking $\leq 16$ years than for initiation 17-19 years. In Add Health at 24-34 years, the RR and thus the adjusted AAF were higher than those seen in the NCDS at 33 years. In VACHS at 33 to 40 years, while the proportion of smokers who initiated $<20$ years was similar to other cohorts, a lower RR resulted in the lowest AAF across all cohorts. In the Pelotas cohort, the proportion of smokers who initiated $<20$ years was lower amongst men but higher amongst women than other cohorts. AAF estimates were lower amongst Pelotas men than in Add Health and the NCDS in early adulthood but similar amongst Pelotas women. 
Table 3 shows associations between adolescent initiation of smoking (10-19 years) and adult heavy daily smoking in each cohort (data are shown for NCDS at 50 years and only for Pelotas males due to low numbers amongst females). The cohorts provide the necessary longitudinal data to calculate the strength of association between adolescent smoking initiation and current adult smoking, allowing for quitting and relapse. The RR across the cohorts ranged from 3.7 (in VAHCS) to 11.4 (heavy smokers in Add Health), with the commonest RR being between $6 \& 8$. We used these RR to estimate AAFs for subsequent analyses including a much wider range of countries for which there are cross-sectional data on either the current prevalence of smoking in adolescence $(P e)$ or the proportion of current smokers who initiated in adolescence $(P d)$.

Figure 1 shows AAFs for 19 countries participating in GATS (2008-2012), estimated from the proportion of 25-34 year male daily smokers who began daily smoking in adolescence $(P d)$ and RR from 4 to 11; the proportions initiating in adolescence in GATS ranged from $41.0 \%$ in China to $86.8 \%$ in Argentina, resulting in AAFs for an RR of 8 ranging from $36 \%$ in China to 76\% in Argentina. Detail for both sexes are shown in the Appendix (Tables A2 \& A3). For females in GATS, proportions initiating in adolescence ranged from $62 \%$ in the Ukraine to 84\% in Uruguay, resulting in AAF's from 54 to 74 in those countries, although very low prevalence of smoking in many Asian and African countries limited the estimation of AAFs. The impact on AAFs of differing proportions of adult smokers initiating in adolescence is modelled for RR from 4 to 11 in Appendix Figure A1.

Figure 2 shows a global map of AAF estimates for 155 countries calculated from the most recently collected data on global prevalence of current smoking in 13-15 year old males $(\mathrm{Pe})$, and an RR of 8 (chosen as the midpoint in the AAF range 4 to 11 across regular and heavy smoking). 
The prevalence of smoking amongst males ranged from 3 to $66 \%$ (median 20.9\%), resulting in $\mathrm{AAFs}$ for $\mathrm{RR}=8$ from 15.9 to $82.2 \%$ (median $59.4 \%$ ). For young women, current smoking ranged from 1.5 to $54.1 \%$ (median $13.2 \%$ ) resulting in AAFs for $\mathrm{RR}=8$ from 9.5 to $79.1 \%$ (median 48.0\%). See Appendix for detailed data by country (Table A4) and AAF maps for RR of 4 and 11 for males and 4, 8 and 11 for females. The impact of differing proportions of adolescents smoking on AAFs is modelled for a range of RR in Appendix Figure A7.

Appendix Figure 1 shows the impact on calculated AAFs in the 4 longitudinal cohorts of different counter-factual scenarios from reducing adult smoking to nil (as shown in all other tables and figures) to reduction to 5, 10 and $15 \%$. AAFs remain high in scenarios where adult smoking is reduced to 5 or $10 \%$ of adults smoking.

Ethical review: No new ethical review permissions were required for these secondary data analyses of existing historical cohorts. 


\section{DISCUSSION}

The contribution of adolescence to adult smoking burden is high, with $50-72 \%$ of adult smoking related to adolescent initiation in the longitudinal cohorts studied here. Initiation in young people $\leq 16$ years was more strongly associated with adult smoking burden than initiation later in adolescence. We found effects to be similar across older and more contemporary cohorts in high and middle income countries. Our findings in these cohorts took into account recent secular trends towards fewer adolescents ever smoking and higher quitting rates amongst adults. The contribution of adolescence increased rather than diminished with cohort ageing (in the NCDS), and was greatest for heavy smokers, who were more likely to initiate in adolescence and less likely to quit. AAFs estimated in 19 LMIC for males in the GATS study were similarly high in all countries with the exception of China, Vietnam and Nigeria and with AAFs in Russia, Argentina and Uruguay in excess of those found in our longitudinal cohorts. The range of AAFs estimated from global youth smoking prevalence data again showed a high contribution of adolescence to adult smoking in most countries, particularly in Europe, Africa and the Americas.

The global adolescent contribution to adult smoking will rise with continuing trends towards earlier age of initiation across most LMIC. The mean age of smoking initiation amongst men has now fallen into the teens in all GATS countries with the exception of China, with younger cohorts in all countries showing ever-younger age of initiation and similar trends amongst young women.(2) The contribution of adolescence will be greatest where most smokers persist long-term in smoking after initiation, due to either high levels of nicotine dependence due to high consumption, a lack of public health focus on quitting or low availability of quitting programmes, resulting in a high RR between adolescent and adult smoking. While we were unable to identify other LMIC cohorts with longitudinal data to include in analyses, a recent global survey identified that long-term persistent smoking after initiation varied from $27 \%$ in Nigeria to $75 \%$ in India and $84 \%$ in China(20) and other studies 
have reported very low quit rates in China and India,(2) suggesting the RR between adolescent and adult smoking in these countries is likely to be high. Associations between adolescent and adult smoking are also likely to be high where high average doses of tobacco promote dependence. Countries with high consumption levels ( $\geq 20$ cigarettes per day per smoker) and a high adult smoking prevalence include China, Greece, Ireland, Italy, Japan, Kuwait, Korea, the Philippines, Uruguay, Switzerland, and many Eastern European countries.(21) Together with data from the GYTS shown above, and evidence that adolescent smoking prevalence is rising in many low and middle income countries,(22) these data suggest that the adolescent contribution to adult smoking for many LMIC is likely to be similar to that shown in our cohorts.

The concepts presented here have implications beyond that of tobacco control. Similar AAFs could be calculated for other NCD risk factors that are largely initiated or modified in adolescence, in particular, alcohol use, physical inactivity and obesity. Understanding the contribution of adolescence to later burden of disease would allow the formulation of NCD strategies that included prevention in adolescence, particularly timely given that today's adolescents will begin to encounter NCD-related premature mortality soon after 2025 . For tobacco control, our findings argue for a rebalancing of initiatives to include a greater focus on prevention of initiation amongst adolescents alongside efforts to help adults stop smoking. Today's children and young people form the majority of the estimated 1 billion who will die of smoking-related diseases during the $21^{\text {st }}$ century.(23) Investment in smoking initiation prevention is a longer-term strategy than adult cessation interventions, with the latter being essential to reduce the immediate tobacco-related burden(24) and to achieve short-term targets such as a reduction in premature NCD mortality by $25 \%$ by 2025 .(25) Yet adolescent smoking can change rapidly over a short time span as, unlike cessation efforts, it is less limited by nicotine dependence.(26) Further, minor changes in adolescent initiation may have large consequences: a recent study estimated that a $1 \%$ reduction in proportions 
of US adolescents ever trying cigarettes would reduce lifetime national tobacco-related costs by approximately $\$ 1$ billion.(27)

The most effective tobacco control interventions are those which have traction across the population of both current and future smokers, including taxation and pricing controls, advertising bans and reduction of smoking in public places.(28) Young people are particularly sensitive to tailored pricing, availability and marketing controls, $(29,30)$ and plain packaging of tobacco may be effective in reducing adolescent smoking initiation(31) and increasing quitting.(32) The most effective individual-level interventions for adolescents are those that work in partnership with young people and address the social contexts of health behaviours,(33) and a greater focus is needed engagement of youth partnerships, particularly in LMIC. Also needed are better information systems in order to be able to formulate and monitor effective actions in adolescence, particularly given the rapid pace of change in tobacco use globally.

In countries with low but rising prevalence of tobacco use, prevention of initiation offers the greatest potential to prevent rising tobacco-related burden. In countries where smoking cessation possibilities are limited by high levels of nicotine dependence or by lack of availability of cessation opportunities, prevention of initiation may offer a more achievable opportunity to control tobacco use. In countries with a record of success in reduction of smoking prevalence, prevention of initiation offers the best prospects of an 'end-game' for tobacco.

While the elimination of smoking remains the ultimate goal, we showed that the potential benefits of adolescent prevention remain high in scenarios where the prevalence of adult smoking is reduced from its current $31 \%$ global prevalence to the $5 \%$ target identified by the Lancet NCD Group(5) or in a more pragmatic $10-15 \%$ target. 
It is possible that greater preventive efforts in adolescence may simply shift smoking initiation later. However, this is unlikely given that contemporary cohorts are initiating earlier in adolescence and evidence that that puberty and adolescent brain development make adolescence a critical window for initiation of risk behaviours.(34) Equally, our AAFs may be under-estimates, as the small numbers who currently initiate regular smoking after adolescence may also be positively influenced by prevention strategies encountered in adolescence. Further, an increased focus on prevention of smoking initiation in adolescence may have benefits for other risk behaviours, given evidence that correlations between health behaviours is very strong in this age group and that interventions may prevent more than one risk behaviour.(35)

\section{Strengths and limitations}

Our main findings were based upon 4 large longitudinal cohort studies, 2 nationally representative and two regional cohorts including one from a middle income country, each with smoking prevalence similar to national populations.(15) We used two risk-based(36) alternative equations for PAF estimation and then calculated adjusted AAFs using wellaccepted methods for cohort studies.(16) There is a strong causal dependence of the outcome (adult smoking) on the exposure (adolescent smoking initiation), and thus our calculation of the AAF is likely to represent a true aetiological fraction(36) and our scenario satisfies the assumptions necessary to estimate valid and meaningful PAFs.(37) We adjusted analyses for socioeconomic status and sex, although socioeconomic measures differed between cohorts. While our measures of smoking were all self-report, the prevalence of adult smoking in each cohort was highly similar to recent national data.

We applied the RR identified from our longitudinal cohorts to estimate AAFs from >155 LMIC using contemporary real-world data. While GYTS data on 13-15 year olds underestimates the totality of adolescent smoking, and secular trends mean that GATS data on proportions 
initiating in adolescence are now likely underestimates, the AAFs identified from this modelling were similar to those identified from the cohort studies.

Retrospective recall of age of initiation of smoking is open to forward telescoping, where initiation is recalled as more recent as cohorts age.(38) The direction of this bias would be to reduce the proportion initiating within adolescence, thus underestimating AAFs. We minimised this bias by including contemporary data from within adolescence in each cohort. The GATS analyses, where retrospective reporting was used, are more open to this bias.

Adult smoking prevalence is an imperfect proxy for disease burden relating to tobacco, yet we believe it is the most appropriate outcome to study given that tobacco burden is very largely driven by the numbers of adult smokers. We recognise that the cohorts we used derive from different regions and different historical periods, and were followed up at differing ages. While the broad similarity of findings across cohorts is reassuring, and we were able to assess aging effects in the NCDS, we were not able to disentangle effects of historical period and aging.

\section{Conclusions}

We demonstrate an innovative method for quantifying the contribution of adolescence to the life course burden of tobacco use, the key global NCD risk factor. Our findings indicate that actions are needed that target future as well as current smokers, particularly in LMIC. Given that many of the top ten risk factors for global burden of disease are initiated in adolescence, the high level of tracking of behaviours into adult life and the very strong associations between health risks in adolescence,(39) transformational health system responses to end premature mortality from NCDs must include a greater focus in adolescence.(40) 


\section{Competing Interests}

All authors declare that they have no competing interests.

All authors declare they have not received funding from the tobacco industry.

\section{Author contributions}

RV and DH had the idea for the study. RV led the writing of the study and undertook the analyses of all cohorts except the Add Health cohort. DH undertook the analyses in the Add Health cohort and contributed to writing the paper. JM \& BH provided the Pelotas data, assisted in analyses of the Pelotas data and contributed to writing the paper. AM \& GP contributed to the ideas underlying the paper and contributed to writing the paper.

\section{Funding}

No funds were obtained for these secondary analyses of existing datasets. 
Table 1. Associations between adolescent smoking (initiation 10-19 years) and daily adult smoking

Table shows proportions of regular (any daily cigarettes) smokers in adulthood by smoking status in adolescence (whether initiated being a regular smoker any time in adolescence (10-19 years). The Table then shows the proportion of adult smokers at that age who initiated regular smoking in adolescence, the risk ratio (RR) for being an adult smoker related to adolescence smoking, the adolescent attributable fraction (AAF) for adult smoking, and the adjusted AAF (adjusted for socioeconomic status in adolescence and adulthood and sex).

\begin{tabular}{|c|c|c|c|c|c|c|c|}
\hline \multirow[b]{2}{*}{$\begin{array}{l}\text { Status in } \\
\text { adolescence }\end{array}$} & \multirow[b]{2}{*}{$\begin{array}{l}\text { Status in } \\
\text { adulthood }\end{array}$} & \multicolumn{2}{|c|}{ NCDS cohort } & \multirow{2}{*}{$\begin{array}{c}\text { Add Health } \\
\text { cohort at 24- } \\
34 y r s \\
N=14675\end{array}$} & \multirow{2}{*}{$\begin{array}{c}\text { VAHCS cohort age } \\
33 \text { to } 40 \text { years } \\
N=1348\end{array}$} & \multicolumn{2}{|c|}{ Pelotas cohort at $\mathbf{3 0}$ years } \\
\hline & & $\begin{array}{c}\text { Age } 50 \text { years } \\
\mathrm{N}=\mathbf{7 7 7 6}\end{array}$ & $\begin{array}{l}\text { Persistent smoker } \\
\text { at } 2 \text { of } 3 \text { waves } \\
\mathrm{N}=\mathbf{8 8 7 7}\end{array}$ & & & $\begin{array}{c}\text { Males } \\
N=1687\end{array}$ & $\begin{array}{l}\text { Females } \\
\mathrm{N}=1166\end{array}$ \\
\hline \multirow[t]{3}{*}{ Adolescent smoker } & Adult smoker & 1231 & 1679 & 3454 & 176 & 282 & 293 \\
\hline & Nonsmoker & 2054 & 1990 & 2677 & 434 & 219 & 384 \\
\hline & Total & 3285 (42.2\%) & $3669(41.3 \%)$ & $6133(41.8 \%)$ & $610(45.2 \%)$ & $501(29.7 \%)$ & $677(58.1 \%)$ \\
\hline \multirow[t]{3}{*}{ Non smoker } & Adult smoker & 278 & 436 & 691 & 57 & 116 & 33 \\
\hline & Nonsmoker & 4213 & 4772 & 7851 & 681 & 1070 & 456 \\
\hline & Total & 4491 (57.8\%) & $5208(58.7 \%)$ & $8542(58.2 \%)$ & 738 (54.8\%) & $1186(70.3 \%)$ & 489 (41.9\%) \\
\hline \multicolumn{2}{|c|}{$\%$ initiated in adolescence } & $81.6 \%$ & $79.4 \%$ & $83.3 \%$ & $75.5 \%$ & $70.9 \%$ & $89.9 \%$ \\
\hline \multicolumn{2}{|l|}{ Risk ratio $(95 \% \mathrm{Cl})$} & $6.1(5.4,6.8)$ & $5.5(5.0,6.0)$ & $7.0(6.4,7.7)$ & $3.7(2.8,4.9)$ & $5.8(4.8,7.0)$ & $6.4(4.6,9.0)$ \\
\hline \multicolumn{2}{|l|}{ AAF } & $68.1 \%$ & $64.9 \%$ & $71.3 \%$ & $55.3 \%$ & $58.5 \%$ & $75.9 \%$ \\
\hline \multirow{2}{*}{\multicolumn{2}{|c|}{ Adjusted AAF (95\% }} & $69.1 \%$ & $68.4 \%$ & $70.4 \%$ & $50.2 \%$ & $56.9 \%$ & $71.5 \%$ \\
\hline & & $(65.3,72.5)$ & $(65.0,71.6)$ & $(67.2,73.3)$ & $(38.8,59.4)$ & $(49.9,62.8)$ & $(60.9,79.2)$ \\
\hline
\end{tabular}


Notes: Adjusted AAF is adjusted for gender and socioeconomic status. 
Table 2. Associations between adolescent smoking initiated $\leq 16$ years or 17-19 years and any daily smoking in adulthood

Table shows proportions of regular (daily cigarette smoking) smokers by smoking status in adolescence (whether initiated being a regular smoker who initiated $\leq 16$ years or initiated 17-19 years). For each initiation period, the table then shows the proportion of adult smokers at that age who initiated regular smoking in adolescence, the risk ratio (RR) for being an adult smoker related to adolescence smoking, the adolescent attributable fraction (AAF) for adult smoking.

\begin{tabular}{|c|c|c|c|c|c|c|c|c|c|c|c|c|c|}
\hline \multirow[b]{3}{*}{$\begin{array}{l}\text { Status in } \\
\text { adolescence }\end{array}$} & \multirow[b]{3}{*}{$\begin{array}{l}\text { Status in } \\
\text { adulthood }\end{array}$} & \multicolumn{6}{|c|}{ Initiation $\leq 16$ years } & \multicolumn{6}{|c|}{ Initiation $17-19$ years } \\
\hline & & \multicolumn{2}{|c|}{ NCDS cohort } & \multirow{2}{*}{$\begin{array}{l}\text { Add Health } \\
\mathrm{N}=14618\end{array}$} & \multirow{2}{*}{$\begin{array}{l}\text { VAHCS } \\
\text { cohort } \\
\mathrm{N}=1343\end{array}$} & \multicolumn{2}{|c|}{ Pelotas } & \multicolumn{2}{|c|}{ NCDS cohort } & \multirow{2}{*}{$\begin{array}{l}\text { Add Health } \\
\mathrm{N}=12022\end{array}$} & \multirow{2}{*}{$\begin{array}{l}\text { VAHCS } \\
\text { cohort } \\
\mathrm{N}=955\end{array}$} & \multicolumn{2}{|c|}{ Pelotas } \\
\hline & & $\begin{array}{l}50 \text { years } \\
\mathrm{n}=7397\end{array}$ & $\begin{array}{c}\text { Persistent } \\
\text { smoker } \\
\mathrm{N}=8504\end{array}$ & & & $\begin{array}{c}\text { Males } \\
\mathrm{N}=1687\end{array}$ & $\begin{array}{l}\text { Females } \\
\mathrm{N}=1042\end{array}$ & $\begin{array}{l}50 \text { years } \\
N=5767\end{array}$ & $\begin{array}{c}\text { Persistent } \\
\text { smoker } \\
\mathrm{N}=6454\end{array}$ & & & $\begin{array}{c}\text { Males } \\
\mathrm{N}=1364\end{array}$ & $\begin{array}{l}\text { Females } \\
\mathrm{N}=736\end{array}$ \\
\hline \multirow[t]{4}{*}{$\begin{array}{l}\text { Adolescent } \\
\text { smoker }\end{array}$} & $\begin{array}{l}\text { Adult } \\
\text { smoker }\end{array}$ & 924 & 1329 & 2359 & 173 & 246 & 251 & 307 & 350 & 1090 & 18 & 93 & 88 \\
\hline & Non-smoker & 1359 & 1342 & 1753 & 423 & 184 & 294 & 695 & 648 & 915 & 66 & 75 & 123 \\
\hline & Total & 2283 & 2671 & 4114 & 596 & 430 & 545 & 1002 & 998 & 2005 & 84 & 168 & 211 \\
\hline & & $(30.9 \%)$ & $(31.4 \%)$ & (28.1\%) & $(44.4 \%)$ & $(25.5 \%)$ & $(52.3 \%)$ & $(17.3 \%)$ & $(15.5 \%)$ & $(16.7 \%)$ & $(8.8 \%)$ & $(12.3 \%)$ & $(14.6 \%)$ \\
\hline \multirow[t]{3}{*}{ Non-smoker } & $\begin{array}{l}\text { Adult } \\
\text { smoker }\end{array}$ & 452 & 642 & 1753 & 59 & 152 & 75 & 414 & 583 & 1443 & 67 & 122 & 43 \\
\hline & Non-smoker & 4662 & 5191 & 8756 & 688 & 1105 & 422 & 4351 & 4873 & 8574 & 804 & 1074 & 482 \\
\hline & Total & $\begin{array}{c}5114 \\
(69.1 \%)\end{array}$ & $\begin{array}{c}5833 \\
(68.6 \%)\end{array}$ & $\begin{array}{l}10504 \\
(71.9 \%)\end{array}$ & $\begin{array}{c}747 \\
(55.6 \%)\end{array}$ & $\begin{array}{c}1257 \\
(74.5 \%)\end{array}$ & $\begin{array}{c}497 \\
(47.7 \%)\end{array}$ & $\begin{array}{c}4765 \\
(82.6 \%)\end{array}$ & $\begin{array}{c}5456 \\
(84.5 \%)\end{array}$ & $\begin{array}{c}10017 \\
(83.3 \%)\end{array}$ & $\begin{array}{c}871 \\
(91.2 \%)\end{array}$ & $\begin{array}{c}1196 \\
(87.7 \%)\end{array}$ & $\begin{array}{c}525 \\
(85.4 \%)\end{array}$ \\
\hline \multicolumn{2}{|c|}{$\%$ initiated in adolescence } & $67.2 \%$ & $67.4 \%$ & $57.5 \%$ & $74.6 \%$ & $61.8 \%$ & $77.0 \%$ & & & & & & \\
\hline \multicolumn{2}{|c|}{ Risk ratio $(95 \% \mathrm{Cl})$} & 4.6 & 4.5 & 3.4 & 3.7 & 4.7 & 3.1 & 3.5 & 3.3 & 3.8 & 2.7 & 5.4 & 5.1 \\
\hline
\end{tabular}




\begin{tabular}{|c|c|c|c|c|c|c|c|c|c|c|c|c|}
\hline & $(4.1,5.1)$ & $(4.2,4.9)$ & $(3.2,3.7)$ & $(2.8,4.8)$ & $(4.0,5.6)$ & $(2.4,3.8)$ & $(3.1,4.0)$ & $(2.9,3.7)$ & $(3.5,4.1)$ & $(1.7,4.5)$ & $(4.4,6.7)$ & $(3.7,7.1)$ \\
\hline AAF & $52.5 \%$ & $52.5 \%$ & $40.8 \%$ & $54.3 \%$ & $48.7 \%$ & $51.8 \%$ & $30.5 \%$ & $26.1 \%$ & $31.6 \%$ & $13.6 \%$ & $35.3 \%$ & $54.0 \%$ \\
\hline \multirow[t]{2}{*}{ Adjusted AAF (95\% Cl) } & $53.9 \%$ & $53.3 \%$ & $39.6 \%$ & $49.2 \%$ & $48.1 \%$ & $47.4 \%$ & $28.2 \%$ & $26.9 \%$ & $32.0 \%$ & $12.7 \%$ & $34.0 \%$ & $50.6 \%$ \\
\hline & $(50.1,57.4)$ & $(49.9,56.5)$ & $(36.4,42.7)$ & $(38.0,58.4)$ & $(41.6,53.9)$ & $(36.7,56.3)$ & $(23.7,32.4)$ & $(22.9,30.8)$ & $(29.3,34.7)$ & $(3.9,20.7)$ & $(26.8,40.6)$ & $(38.2,60.5$ \\
\hline
\end{tabular}

Notes: Adjusted AAF is adjusted for gender and socioeconomic status.

Analyses for initiation 17-19 years exclude those who initiated smoking <=16years, thus sample size is smaller. Proportion initiated in adolescence not calculated for 17-19 year olds as denominator excludes smokers who initiated $\leq 16 y e a r s$. 
Table 3. Associations between heavy smoking in adulthood and adolescent smoking initiation 10-19 years

Table shows proportions of heavy smoking in adulthood by smoking status in adolescence (whether initiated being a regular smoker any time in adolescence (10-19 years). The Table then shows the proportion of heavy smokers at that age who initiated regular smoking in adolescence, the risk ratio (RR) for being an adult smoker related to adolescence smoking, the adolescent attributable fraction (AAF) for adult smoking, and the adjusted AAF (adjusted for socioeconomic status in adolescence and adulthood and sex).

\begin{tabular}{|c|c|c|c|c|c|}
\hline & & $\begin{array}{c}\text { NCDS cohort at } 50 \\
\text { years }\end{array}$ & $\begin{array}{l}\text { Add Health cohort at 24- } \\
\text { 34yrs }\end{array}$ & $\begin{array}{c}\text { VAHCS cohort age } 33 \text { to } \\
40 \text { years }\end{array}$ & Pelotas males at 30 years \\
\hline Status in adolescence & Status in adulthood & $N=7776$ & $N=14675$ & $N=1352$ & $N=1687$ \\
\hline \multirow[t]{4}{*}{ Adolescent smoker } & Adult smoker & 530 & 1133 & 78 & 133 \\
\hline & Nonsmoker & 2755 & 4998 & 536 & 368 \\
\hline & Total & 3285 & 6131 & 614 & 501 \\
\hline & & $(42.2 \%)$ & $(41.8 \%)$ & $(45.4 \%)$ & $(29.7 \%)$ \\
\hline \multirow[t]{4}{*}{ Non smoker } & Adult smoker & 123 & 138 & 14 & 40 \\
\hline & Nonsmoker & 4368 & 8406 & 724 & 1146 \\
\hline & Total & 4491 & 8544 & 738 & 1186 \\
\hline & & $(57.8 \%)$ & $(58.2 \%)$ & $(54.6 \%)$ & $(70.3 \%)$ \\
\hline \multicolumn{2}{|l|}{$\%$ initiated in adolescence } & $81.2 \%$ & $89.1 \%$ & $84.8 \%$ & $76.9 \%$ \\
\hline \multirow{2}{*}{\multicolumn{2}{|c|}{ Risk ratio $(95 \% \mathrm{Cl})$}} & $5.9(4.9,7.1)$ & $11.4(9.3,14.4)$ & $6.7(3.8,11.7)$ & 7.9 \\
\hline & & & & & $(5.6,11.0)$ \\
\hline \multicolumn{2}{|l|}{ AAF } & $67.4 \%$ & $81.4 \%$ & $72.1 \%$ & $67.1 \%$ \\
\hline \multirow{2}{*}{\multicolumn{2}{|c|}{ Adjusted AAF (95\% CI) }} & $65.2 \%$ & $80.8 \%$ & $66.90 \%$ & $67.0 \%$ \\
\hline & & $(58.6,70.7)$ & $(76.0,84.6)$ & $(47.2,79.2)$ & $(55.6,75.4)$ \\
\hline
\end{tabular}


Notes. Attributable fraction adjusted for sex and socioeconomic status for the NCDS, Add Health and VAHCS studies and for socioeconomic status in the Pelotas cohort. 
Figure 1. AAFs for smoking amongst males aged 24-35 years based on RR from 4 to 11 in 19 countries participating in GATS 2008-2012 
Figure 2. Estimates of AAF for males in 155 countries calculated from current smoking prevalence amongst 13-15 year olds and an RR of 8 
Appendix Figure 1. Adjusted AAFs for adult daily smoking in NCDS, Pelotas, Add Health \& VAHCS for counter-factual scenarios from $0 \%$ to $15 \%$ smoking prevalence in adulthood 


\section{References}

[1] Lozano R, Naghavi M, Foreman K, et al. Global and regional mortality from 235 causes of death for 20 age groups in 1990 and 2010: a systematic analysis for the Global Burden of Disease Study 2010. Lancet 2012;380:2095-2128.

[2] Giovino GA, Mirza SA, Samet JM, et al. Tobacco use in 3 billion individuals from 16 countries: an analysis of nationally representative cross-sectional household surveys. Lancet 2012;380:668-679.

[3] Degenhardt L, Chiu WT, Sampson N, et al. Toward a global view of alcohol, tobacco, cannabis, and cocaine use: findings from the WHO World Mental Health Surveys. PLoS Med 2008;5:e141.

[4] Kontis V, Mathers CD, Rehm J, et al. Contribution of six risk factors to achieving the $25 \times 25$ non-communicable disease mortality reduction target: a modelling study. Lancet 2014;384:427-437.

[5] Beaglehole R, Bonita R, Horton R, et al. Priority actions for the non-communicable disease crisis. Lancet 2011;377:1438-1447.

[6] Patton GC, Sawyer SM, Santelli JS, et al. Our future: a Lancet commission on adolescent health and wellbeing. Lancet 2016;387:2423-2478.

[7] Global health risks: Mortality and burden of disease attributable to selected major risks. Geneva: World Health Organisation, 2009.

[8] Seto MC, Kjellgren C, Priebe G, et al. Sexual coercion experience and sexually coercive behavior: a population study of Swedish and Norwegian male youth. Child Maltreat 2010;15:219-228.

[9] Norstrom T, Pape H. Associations between adolescent heavy drinking and problem drinking in early adulthood: implications for prevention. J Stud Alcohol Drugs 2012;73:542548.

[10] Frieden TR, Bloomberg MR. How to prevent 100 million deaths from tobacco. Lancet 2007;369:1758-1761.

[11] Elliot J, Vaitilingam R. Now we are 50: Key findings from the National Child Development Study. London: Centre for Longitudinal Studies, Institute of Education, University of London; 2008.

[12] Add Health Study: About Public-Use Data. Available at: http://www.cpc.unc.edu/projects/addhealth/data/publicdata Accessed 28 October 2013. [13] Barros FC, Victora CG, Horta BL, et al. [Methodology of the Pelotas birth cohort study from 1982 to 2004-5, Southern Brazil]. Revista de saude publica 2008;42 Suppl 2:7-15. [14] Patton GC. 2000 stories: The Victorian Adolescent Health Cohort Study. Available at: http://www.mcri.edu.au/research/research-projects/2000stories/Accessed 10 August 2014. [15] Benichou J. A review of adjusted estimators of attributable risk. Statistical methods in medical research 2001;10:195-216.

[16] Newson RB. Scenario comparisons: How much good can we do? Presented the 18th United Kingdom Stata Users' Group Meeting, 13-14 September, 2012. . Available at: http://ideas.repec.org/p/boc/usug12/01.html.

[17] Hanley JA. A heuristic approach to the formulas for population attributable fraction. Journal of Epidemiology and Community Health 2001;55:508-514.

[18] Steenland K, Armstrong B. An overview of methods for calculating the burden of disease due to specific risk factors. Epidemiology 2006;17:512-519.

[19] Current users of any tobacco product (youth rate): Global Health Observatory of the World Health Organisation. Accessed 19-2-2015.

[20] Troost JP, Barondess DA, Storr CL, et al. An updated global picture of cigarette smoking persistence among adults. Journal of epidemiology and global health 2012;2:135-144. 
[21] Ng M, Freeman MK, Fleming TD, et al. Smoking prevalence and cigarette consumption in 187 countries, 1980-2012. JAMA 2014;311:183-192.

[22] Hipple B, Lando H, Klein J, et al. Global teens and tobacco: a review of the globalization of the tobacco epidemic. Current problems in pediatric and adolescent health care 2011;41:216-230.

[23] Eriksen M, Mackay J, Ross H. The tobacco atlas. 4th 'edition'. Atlanta, GA: American Cancer Society, 2012.

[24] Hill D. Why we should tackle adult smoking first. Tob Control 1999;8:333-335.

[25] World Health Organisation. Global action plan for the prevention and control of noncommunicable diseases 2013-2020. Geneva: World Health Organisation; 2013.

[26] Pierce JP, White VM, Emery SL. What public health strategies are needed to reduce smoking initiation? Tob Control 2012;21:258-264.

[27] Wang LY, Michael SL. Long-term health and medical cost impact of smoking prevention in adolescence. J Adolesc Health 2015;56:160-166.

[28] White VM, Warne CD, Spittal MJ, et al. What impact have tobacco control policies, cigarette price and tobacco control programme funding had on Australian adolescents' smoking? Findings over a 15-year period. Addiction 2011;106:1493-1502.

[29] Tauras JA, Huang J, Chaloupka FJ. Differential impact of tobacco control policies on youth sub-populations. Int J Environ Res Public Health 2013;10:4306-4322.

[30] Sim Smoke model: Readers Guide. Bethesda, MA: Cancer Intervention and Surveillance Modelling Network, National Cancer Institute, National Institutes of Health; 2012.

[31] Czoli CD, Hammond D. Cigarette packaging: Youth perceptions of "natural" cigarettes, filter references, and contraband tobacco. J Adolesc Health 2014;54:33-39.

[32] Young JM, Stacey I, Dobbins TA, et al. Association between tobacco plain packaging and Quitline calls: a population-based, interrupted time-series analysis. Med J Aust 2014;200:2932.

[33] Campbell R, Starkey F, Holliday J, et al. An informal school-based peer-led intervention for smoking prevention in adolescence (ASSIST): a cluster randomised trial. Lancet 2008;371:1595-1602.

[34] Patton GC, Viner R. Pubertal transitions in health. Lancet 2007;369:1130-1139.

[35] Hale DR, Fitzgerald-Yau N, Viner RM. A systematic review of effective interventions for reducing multiple health risk behaviors in adolescence. Am J Public Health 2014;104:e19-41. [36] Greenland S. Concepts and pitfalls in measuring and interpreting attributable fractions, prevented fractions, and causation probabilities. Ann Epidemiol 2014.

[37] Rockhill B, Newman B, Weinberg C. Use and misuse of population attributable fractions. American Journal of Public Health 1998;88:15-19.

[38] Johnson EO, Schultz L. Forward telescoping bias in reported age of onset: an example from cigarette smoking. Int J Methods Psychiatr Res 2005;14:119-129.

[39] de Walque D. Risking your health: Causes, consequences and interventions to prevent risky behaviours. Washington, D.C.: The World Bank; 2014.

[40] Grand convergence: a future sustainable development goal? Lancet 2014;383:187. 
Figure 2. Estimates of AAF for males in 155 countries calculated from current smoking prevalence amongst 13-15 year olds and an RR of 8

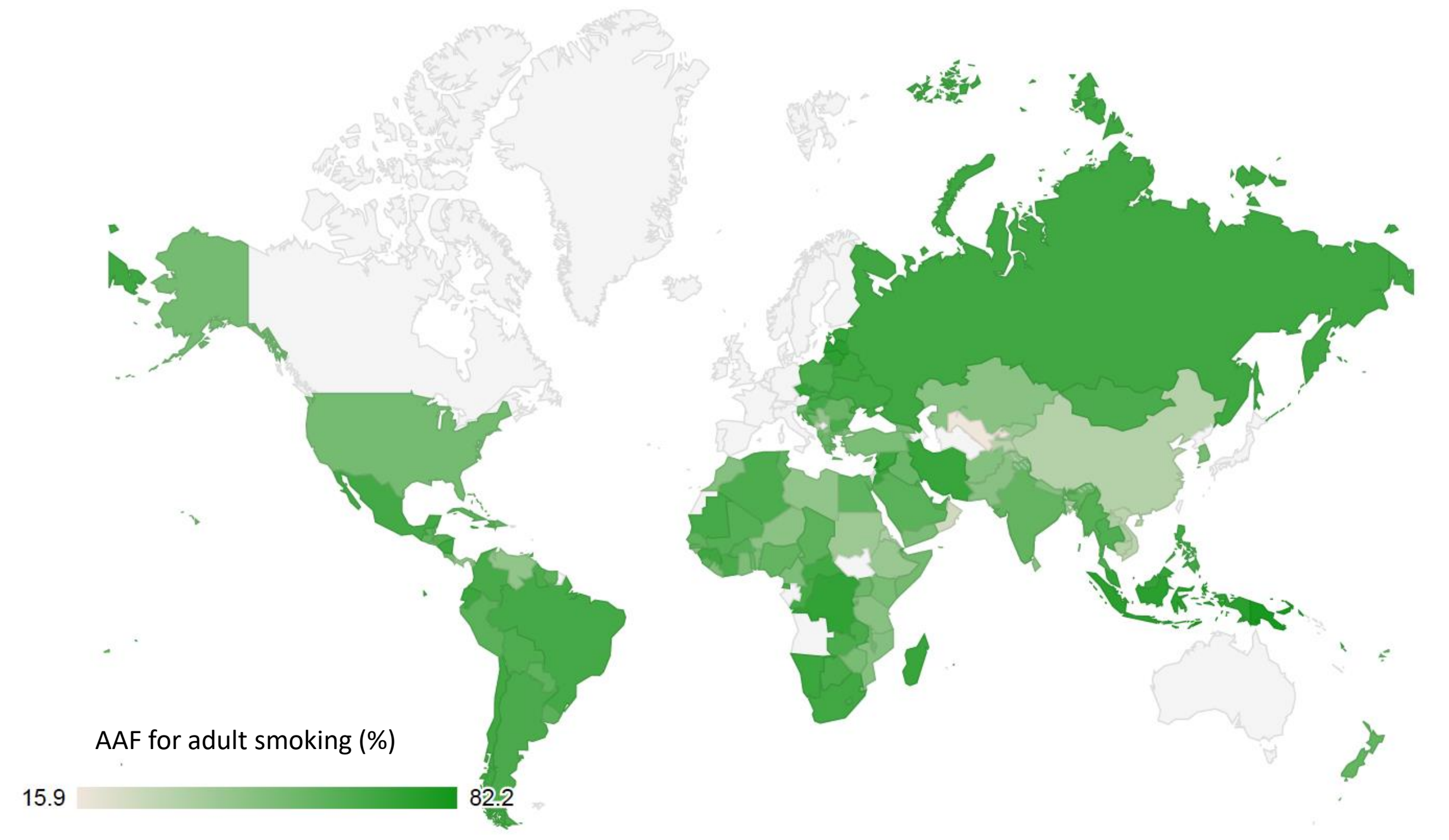

Map shows estimated AAF for each country by colour shade, with darker green indicating higher AAF (range 15.9082.16). Data were drawn from the Global Youth Tobacco Survey (GYTS). 
Adjusted AAFs for adult daily smoking in NCDS, Pelotas, Add Health \& VAHCS for counter-factual scenarios from $0 \%$ to $15 \%$ smoking prevalence in adulthood

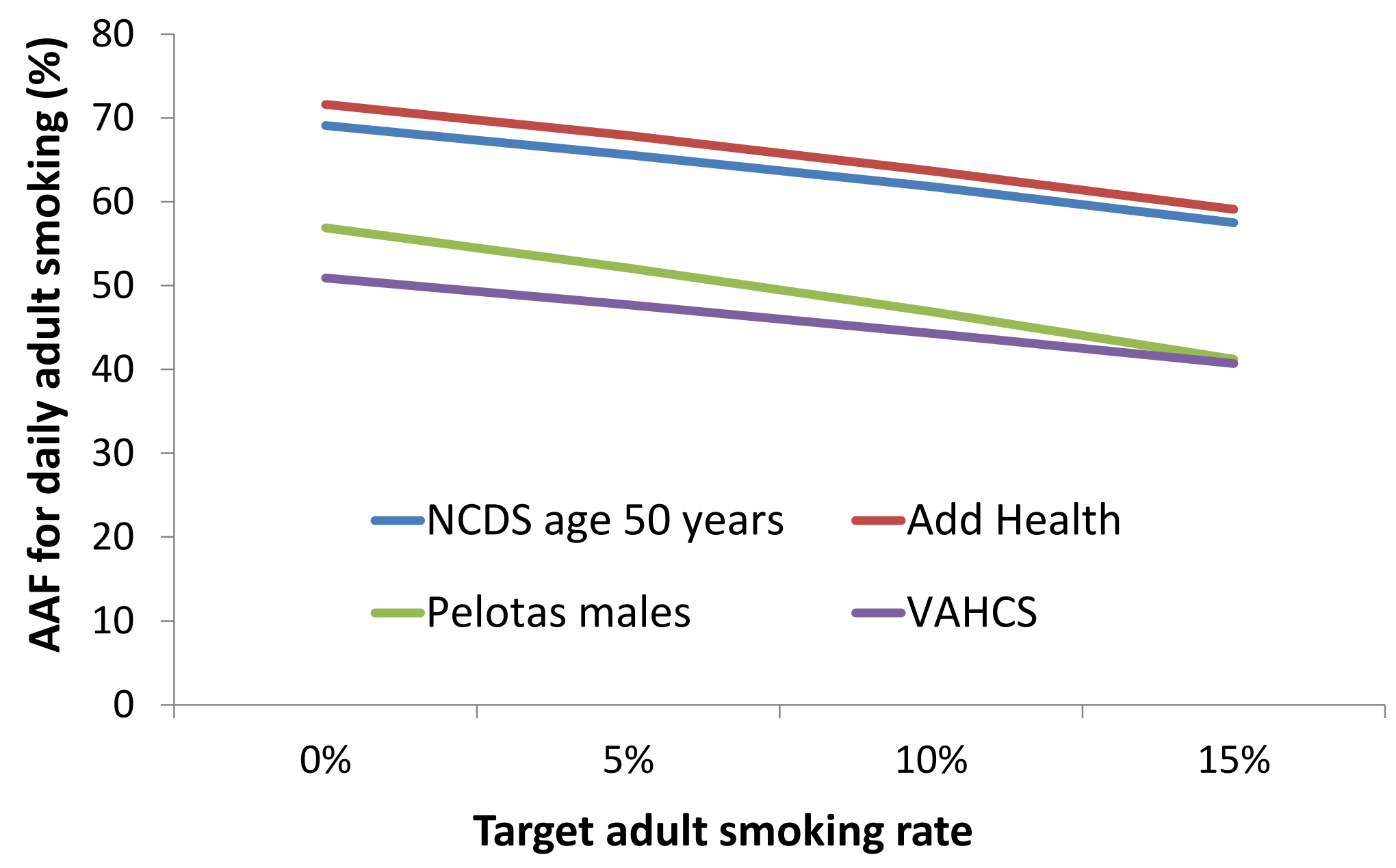

